\title{
Jordens salter
}

\author{
Det er ikke bare i våre dager man er opptatt av kostholdets betydning for helsen. Dr.agr. Bremer innleder sin \\ artikkel i Tidsskriftet nr. 1/1931 slik: «Trui på evna åt mineralstoffi i næringsemna til å lækja og fyrebyggja \\ sjukdom ...» Han drøfter hva det er i jordsmonn og gjødsel som innvirker på næringsinnholdet i maten og gir \\ den «lækjande kraft»og avslutter med en oppfordring til samarbeid mellom medisin og hagebruk for å få nye \\ kunnskaper om våre næringsemner. En slik gransking blir selvfølgelig dyr, men «vi skal her minnast at inntekti \\ av Statens pengelotteri fyrst og framst skal gå til tuberkulosearbeidet og skogsaki, so vi burde kunna få midlar \\ nok til dette arbeid derifrå» (Tidsskr Nor Lægeforen 1931; 51: 6-11).
}

\section{Um verdsetjing av plantemineralstoff som naring.}

Av dr. agr. A. H. Bremer.

Når eg no kjem inn på spurgsmålet um gjødsling i høve til plantenes innhald av mineralemne, so er det fordi eg har grunn til å tru at vi kan løysa til ein viss grad iminsto s purs må $1 \mathrm{um} \mathrm{kva} \mathrm{verd}$ dei einskilde mineralstoff har for menneskeorganis men.

I ein tabell har eg etter E. Wolff teke inn nokre tal som viser innhaldet av mineralstoff i dei viktigaste nærings- og fôremne. I kvar rubrikk står 3 tal: Medeltalet for prosentisk innhald av mineralstoff, og dessutan det største og det minste talet som er funne $i$ analysane. Tali viser at det kan vera store brigde i kor mykje eit næringsemne inneheld av mineralstoff i prosent av turrstoff og endå sværare brigde $\mathrm{i}$ innhaldet av kvart einskilt mineral.

Wolffs samlararbeid er frå 1870-1880. Dei var soleis alt tidleg på det reine med at næringsemni i sitt kjemiske innhald kunde brigda svært.

Frå seinare tid finnst mange arbeid som har stadfesta dei tidlegare. Dei faktorar som har innverknad på det kjemiske innhaldet, er for plantane fyrst og framst verlag, jordart, og innhaldet på tilgjengeleg plantenæring i jordi, dessutan også haustetid, planteart og slag. For produkt frå dyr (mjølk og egg) vil det prosentvise innhald brigda etter den næring dyri har fenge.
Vi kan altså ved å velja jord og ved å tilføre jordi mineralgjødsel, - kali, kalk, natron, jarn m. m. som fosforsure-, svovelsure- eller som klor-salt, til ein viss grad få herredøme over det prosentvise innhald av desse stoff hjå plantane. Sume av desse mineralstoff aukar ogso som regel avlingi: kali-, kalk-, fosforsyregjødsling. (...)

Vel kjend millom jordbruksforskarane er dei resultat som er nådd med gjødselemne som inneheld klor. Dette vil ogso visseleg interessera medisinarane, då det ligg nær å sidestilla desse resultat med den meining Gerson m. fl. har sett fram, at koksalt - klornatrium - har ein nedsetjande verknad på motstandskrafti mot visse sjukdomar. (...)

(...) Men dei nyare resultat i næringsfysiologien for menneskja tyder på at vi må brigde noko på våre synsmåtar, leggja serleg vekt på at grønsaker, frukt og fôr til ku og gjeit inneheld meir mineralstoff. Rettnok veit ikkje næringsfysiologane endå mykje um kva verd kvart einskild mineralstoff har for oss til fyrebyggjing eller heiling av sjukdomar. Dei kan heller ikkje alltid skilja millom den rolle vitamin og den rolle mineralstoff spelar i so måte.

Grønsaksforsøki, Landbrukshøgskulen, Ås, 8. november 1930.

\begin{tabular}{|c|c|c|c|c|c|c|c|c|c|c|c|}
\hline \multirow{2}{*}{ Steffnamn. } & \multirow{2}{*}{ 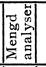 } & \multirow{2}{*}{$\begin{array}{l}\text { Rein } \\
\text { oske. }\end{array}$} & \multicolumn{9}{|c|}{ I 100 deler rein oske. } \\
\hline & & & $\mathrm{K}_{2} \mathrm{O}$. & $\mathrm{Na}_{2} \mathrm{O}$ & Ca. $\mathrm{O}$. & Mg. O. & $\mathrm{Fe}_{2} \mathrm{O}_{3}$ & $\mathrm{P}_{2} \mathrm{O}_{5}$ & S. $\mathrm{O}_{3}$ & $\mathrm{Si}_{2}$ & $\mathrm{Cl}$. \\
\hline Havre. & 57 & $\begin{array}{r}3,12 \\
4,3-2,3\end{array}$ & $\begin{array}{r}17,90 \\
26,2-12,6\end{array}$ & $\begin{array}{r}1,66 \\
5,3-0,0\end{array}$ & $\begin{array}{r}3,60 \\
8,4-1,3\end{array}$ & $\begin{array}{r}7,3 \\
10,8-4,5 \\
\end{array}$ & $\begin{array}{r}1,18 \\
9,1-0,03\end{array}$ & $\begin{array}{r}25,64 \\
35,1-156 \\
\end{array}$ & $\begin{array}{r}1,78 \\
5,3-0,0 \\
\end{array}$ & $\begin{array}{r}39,18 \\
56,0-16,8 \\
\end{array}$ & $\begin{array}{r}0,94 \\
3,3-0,0 \\
\end{array}$ \\
\hline Erter & 40 & $\begin{array}{r}2,73 \\
4,3-2,35 \\
\end{array}$ & $\begin{array}{r}43,10 \\
51,8-35,8 \\
\end{array}$ & $\begin{array}{r}0,98 \\
3,6-0,0 \\
\end{array}$ & $\begin{array}{r}4,81 \\
7,9-1,8\end{array}$ & $\begin{array}{r}7,99 \\
13,0-3,7 \\
\end{array}$ & $\begin{array}{r}0,83 \\
3,8-0,0 \\
\end{array}$ & $\begin{array}{r}35,90 \\
44,4-26,2 \\
\end{array}$ & $\begin{array}{r}3,42 \\
10,4-0,0 \\
\end{array}$ & $\begin{array}{r}0,91 \\
3,0-0,0 \\
\end{array}$ & $\begin{array}{r}1,59 \\
6,5-0,0 \\
\end{array}$ \\
\hline Druve, heile frukti & 7 & $\begin{array}{r}5,19 \\
8,4-3,6\end{array}$ & $\begin{array}{r}56,20 \\
66,5-42,6 \\
\end{array}$ & $\begin{array}{r}1,42 \\
3,6-0,4 \\
\end{array}$ & $\begin{array}{r}10,77 \\
14,4-9,1 \\
\end{array}$ & \begin{tabular}{|r|}
4,21 \\
$5,0-1,9$
\end{tabular} & $\begin{array}{r}0,37 \\
1,3-0-1\end{array}$ & $\begin{array}{r}15,58 \\
27,2-9,4\end{array}$ & $\begin{array}{r}5,62 \\
6,8-3,9 \\
\end{array}$ & $\begin{array}{r}2,75 \\
5,1-0,6\end{array}$ & $\begin{array}{r}1,52 \\
3,0-0,4 \\
\end{array}$ \\
\hline Vinterkveite & 110 & $\begin{array}{r}1,96 \\
2,5-1,64\end{array}$ & $\begin{array}{r}31,16 \\
41,1-23,2 \\
\end{array}$ & $\begin{array}{r}2,07 \\
9,1-0,0 \\
\end{array}$ & $\begin{array}{r}3,25 \\
8,2--0,9 \\
\end{array}$ & $\begin{array}{r}12,06 \\
16,3-9,1\end{array}$ & $\begin{array}{r}1,28 \\
3,0-0,15\end{array}$ & $\begin{array}{r}47,22 \\
53,7-39,2 \\
\end{array}$ & \begin{tabular}{|r|}
0,39 \\
$5,6-0,0$ \\
\end{tabular} & $\begin{array}{r}1,96 \\
5,9-0.0\end{array}$ & $\begin{array}{r}0,32 \\
3,5-0,0 \\
\end{array}$ \\
\hline Poteter & 59 & $\begin{array}{r}3,79 \\
5,8-2,2 \\
\end{array}$ & $\begin{array}{r}60,06 \\
73,6-44,0 \\
\end{array}$ & $\begin{array}{r}2,96 \\
17,5-0,0 \\
\end{array}$ & $\begin{array}{r}2,64 \\
7,2-0,4\end{array}$ & $\begin{array}{r}4,93 \\
13,6-1,3 \\
\end{array}$ & $\begin{array}{r}1,10 \\
7,2-0,0\end{array}$ & $\begin{array}{r}16,86 \\
27,1-8,4\end{array}$ & $\begin{array}{r}6,52 \\
14,9-0,4 \\
\end{array}$ & $\begin{array}{r}2,04 \\
8,1-0,0\end{array}$ & $\begin{array}{r}3,46 \\
12,6-0,7 \\
\end{array}$ \\
\hline Forbeter. . & 19 & $\begin{array}{r}7,58 \\
14,1-4,4\end{array}$ & $\begin{array}{r}52,22 \\
69,4-25,6 \\
\end{array}$ & $\begin{array}{r}16,26 \\
39,2-5,3 \\
\end{array}$ & $\begin{array}{r}3,73 \\
8,8-1,9\end{array}$ & $\begin{array}{r}4,30 \\
7,9-2,1 \\
\end{array}$ & $\begin{array}{r}0,75 \\
3,1-0,3 \\
\end{array}$ & $\begin{array}{r}8,53 \\
13,0-2,0 \\
\end{array}$ & $\begin{array}{r}3,02 \\
6,0-2,0 \\
\end{array}$ & $\begin{array}{r}2,04 \\
10,0-0,0 \\
\end{array}$ & $\begin{array}{r}9,96 \\
35,5-1,9 \\
\end{array}$ \\
\hline Nepe & 32 & $\begin{array}{r}8,01 \\
14,0-4,9 \\
\end{array}$ & $\begin{array}{r}45,40 \\
62,6-26,6 \\
\end{array}$ & $\begin{array}{r}9,84 \\
20,7-0,0 \\
\end{array}$ & $\begin{array}{r}10,60 \\
15,9-5,5 \\
\end{array}$ & $\begin{array}{r}3,69 \\
6,4-1,6 \\
\end{array}$ & $\begin{array}{r}0,81 \\
2, y-0,2\end{array}$ & $\begin{array}{r}12,71 \\
18,9-5,5 \\
\end{array}$ & $\begin{array}{r}11,19 \\
18,1-2,6 \\
\end{array}$ & $\begin{array}{r}1,87 \\
8,0-0,0 \\
\end{array}$ & $\begin{array}{r}5,07 \\
13,4-1,4 \\
\end{array}$ \\
\hline Gulrot & 11 & $\begin{array}{r}5,47 \\
8,0-4,3\end{array}$ & $\begin{array}{r}36,92 \\
55,8-17,0\end{array}$ & $\begin{array}{r}21,17 \\
34,8-10,9\end{array}$ & $\begin{array}{r}11,34 \\
16,5-6,9\end{array}$ & \begin{tabular}{r|}
4,38 \\
$7,3-0,6$
\end{tabular} & $\begin{array}{r}1,01 \\
2,0-0,0\end{array}$ & $\begin{array}{r}12,79 \\
16,4-9,6 \\
\end{array}$ & $\begin{array}{r}6,45 \\
11,7-3,5 \\
\end{array}$ & $\begin{array}{r}2,38 \\
5,7-0,9 \\
\end{array}$ & $\begin{array}{r}4,59 \\
10,5-0,0 \\
\end{array}$ \\
\hline Pastinak & 4 & $\begin{array}{r}4,83 \\
5,3-4,4\end{array}$ & $\begin{array}{r}54,50 \\
65,0-36,1 \\
\end{array}$ & $\begin{array}{r}1,51 \\
6,1-0,0\end{array}$ & $\begin{array}{r}11,44 \\
16,8-7.7\end{array}$ & \begin{tabular}{r|}
5,71 \\
$9,9-0,0$
\end{tabular} & $\begin{array}{r}1,12 \\
2,0-0,0\end{array}$ & $\begin{array}{r}19,52 \\
23,8-15,6\end{array}$ & $\begin{array}{r}5,19 \\
6,5-3,9 \\
\end{array}$ & $\begin{array}{r}1,61 \\
4,1-0,0 \\
\end{array}$ & $\begin{array}{r}3,79 \\
4,7-2,8 \\
\end{array}$ \\
\hline Hovudsalat. . & & $\begin{array}{r}18,03 \\
19,0-17,4\end{array}$ & \begin{tabular}{r|}
37,63 \\
$52,9-25,3$ \\
\end{tabular} & $\begin{array}{r}7,54 \\
15,7-1,9\end{array}$ & $\begin{array}{r}14,68 \\
15,5-14,2\end{array}$ & $\begin{array}{r}6,19 \\
8,5-4,1 \\
\end{array}$ & $\begin{array}{r}5,21 \\
6,5-2,7\end{array}$ & $\begin{array}{r}9,19 \\
10,7-8,4 \\
\end{array}$ & $\begin{array}{r}3,76 \\
5,2-2,8 \\
\end{array}$ & $\begin{array}{r}8,14 \\
9,2-6,5 \\
\end{array}$ & $\begin{array}{r}7,65 \\
11,1-1,9 \\
\end{array}$ \\
\hline Kumjølk. & & \begin{tabular}{c|}
0,721 \\
$0,79-0,49$
\end{tabular} & $\begin{array}{r}24,08 \\
33.3-17,1\end{array}$ & $\begin{array}{r}6,05 \\
13,9-6,9\end{array}$ & $\begin{array}{r}23,17 \\
27,6-17,3\end{array}$ & $\begin{array}{r}2,63 \\
3,9-1,9 \\
\end{array}$ & $\begin{array}{r}0,44 \\
1,4-0,1\end{array}$ & $\begin{array}{r}27,98 \\
31,2-24,8 \\
1\end{array}$ & \begin{tabular}{|r|}
1,26 \\
$3,2-0,0$ \\
\end{tabular} & $\begin{array}{r}0,02 \\
0,2-0,0 \\
\end{array}$ & $\begin{array}{r}13,45 \\
21,3-9,9 \\
\end{array}$ \\
\hline Morsmjølk & & $\begin{array}{c}0,49 \\
1,78-0,14\end{array}$ & $\begin{array}{r}33,79 \\
38,1-29,8 \\
\end{array}$ & $\begin{array}{rr} & 9,12 \\
11,8 & -5,7\end{array}$ & $\begin{array}{r}16,69 \\
18,8-14,8\end{array}$ & $\begin{array}{r}2,16 \\
3,0-0,9 \\
\end{array}$ & $\begin{array}{r}0,22 \\
0,3-0,1\end{array}$ & $\begin{array}{r}22,66 \\
29,1-19,1 \\
\end{array}$ & \begin{tabular}{|r|}
0,95 \\
$2,6-0,0$ \\
\end{tabular} & $\begin{array}{r}0,02 \\
0,1-0,02 \\
\end{array}$ & $\begin{array}{r}18,38 \\
20,4-14,4 \\
\end{array}$ \\
\hline Timoteigras & 9 & $\begin{array}{r}6,82 \\
9,3-5,1\end{array}$ & $\begin{array}{r}34,69 \\
39,8-22,2 \\
\end{array}$ & $\begin{array}{r}1,83 \\
3,1-0,3 \\
\end{array}$ & $\begin{array}{r}8,05 \\
15,6-4,7 \\
\end{array}$ & $\begin{array}{r}3,24 \\
5,5-2,3 \\
\end{array}$ & $\begin{array}{r}0,83 \\
1,5-0,3 \\
\end{array}$ & $\begin{array}{r}11,80 \\
19,1-5,5 \\
\end{array}$ & \begin{tabular}{r|}
2,85 \\
$5,1-1,9$ \\
\end{tabular} & $\begin{array}{r}32,17 \\
44,5-21,5 \\
\end{array}$ & $\begin{array}{r}5,19 \\
13,1-2,4 \\
\end{array}$ \\
\hline $\begin{array}{l}\text { Raudkløver i blø- } \\
\text { ming } \ldots \ldots \ldots \ldots\end{array}$ & 113 & $\begin{array}{r}6,86 \\
9,2-4,5\end{array}$ & $\begin{array}{r}32,29 \\
52,0-8,8\end{array}$ & $\begin{array}{r}1,37 \\
8,9-0,0\end{array}$ & $\begin{array}{r}34,91 \\
53,4-21,9\end{array}$ & $\begin{array}{r}10,90 \\
26,1-5,3\end{array}$ & $\begin{array}{r}1,08 \\
5,0-0,3\end{array}$ & $\begin{array}{r}9,64 \\
15,0-4,0\end{array}$ & $\begin{array}{r}3,23 \\
7,4-1,2\end{array}$ & $\begin{array}{r}2,69 \\
20,2-0,0\end{array}$ & $\begin{array}{r}3,78 \\
11,8-1,2\end{array}$ \\
\hline
\end{tabular}

